REGARDS

SUR LECONOMIE ALLEMANDE

BULLETIN ECONOMIQUE DU CIRAC

\section{Regards sur l'économie allemande}

Bulletin économique du CIRAC

$67 \mid 2004$

Varia

\title{
Compétitivité et réformes
}

BEUCKER Pascal, ÜBERALL Frank, Die Beamten-Republik. Der Staat im Würgegriff seiner Diener? / FITZENBERGER Bernd et al. (eds), Herausforderungen an den Wirtschaftsstandort Deutschland. Wirtschaftspolitisches Memorandum aus wissenschaftlicher Sicht / KEESE Christoph, Rettet den Kapitalismus. Wie Deutschland wieder an die Spitze kommt / NOLTE Paul, Generation Reform. Jenseits der blockierten Republik / STEINGART Gabor, Deutschland. Der Abstieg eines Superstars / WALTER Norbert, DEUTSCH Klaus Günter (eds), Mehr Wachstum für Deutschland. Die Reformagenda

\section{OpenEdition} Journals

Édition électronique

URL : http://journals.openedition.org/rea/3817

DOI : $10.4000 /$ rea.3817

ISBN : 978-2-8218-0830-0

ISSN : 1965-0787

Éditeur

CIRAC

Édition imprimée

Date de publication : 1 juillet 2004

ISSN : 1156-8992

Référence électronique

«Compétitivité et réformes », Regards sur l'économie allemande [En ligne], 67 | juillet 2004, mis en ligne le 08 octobre 2009, consulté le 22 septembre 2020. URL : http://journals.openedition.org/rea/3817 ; DOI : https://doi.org/10.4000/rea.3817

Ce document a été généré automatiquement le 22 septembre 2020.

(c) CIRAC 


\section{Compétitivité et réformes}

BEUCKER Pascal, ÜBERALL Frank, Die Beamten-Republik. Der Staat im Würgegriff seiner Diener? / FITZENBERGER Bernd et al. (eds), Herausforderungen an den Wirtschaftsstandort Deutschland.

Wirtschaftspolitisches Memorandum aus wissenschaftlicher Sicht / KEESE Christoph, Rettet den Kapitalismus. Wie Deutschland wieder an die Spitze kommt / NOLTE Paul, Generation Reform. Jenseits der blockierten Republik / STEINGART Gabor, Deutschland. Der Abstieg eines Superstars / WALTER Norbert, DEUTSCH Klaus Günter (eds), Mehr Wachstum für Deutschland. Die Reformagenda

\section{RÉFÉRENCE}

BEUCKER Pascal, ÜBERALL Frank, Die Beamten-Republik. Der Staat im Würgegriff seiner Diener? Campus Verlag, Francfort/Main, 2004, 276 p. FITZENBERGER Bernd et al. (eds), Herausforderungen an den Wirtschaftsstandort Deutschland. Wirtschaftspolitisches Memorandum aus wissenschaftlicher Sicht, ZEW Wirtschaftsanalysen, vol. 72, Nomos Verlagsgesellschaft, Baden-Baden, 2004, 270 p.

KEESE Christoph, Rettet den Kapitalismus. Wie Deutschland wieder an die Spitze kommt, Hoffmann und Campe Verlag, Hambourg, 2004, 304 p.

NOLTE Paul, Generation Reform. Jenseits der blockierten Republik, Coll. Beck'sche Reihe, Verlag C.H. Beck, Munich, 2004, 256 p.

STEINGART Gabor, Deutschland. Der Abstieg eines Superstars, Piper Verlag, Munich, 2004, 304 p.

WALTER Norbert, DEUTSCH Klaus Günter (eds), Mehr Wachstum für Deutschland. Die Reformagenda, Campus Verlag, Francfort/Main, 2004, 444 p.

Requiem pour l'Allemagne «superstar »... G. STEINGART, journaliste au magazine Der Spiegel, présente un essai sans fard sur la perte de compétitivité de son pays. La critique est constructive, l'Allemagne peut guérir de la sclérose qui frappe son économie et sa société. Nombreux sont actuellement les ouvrages à livrer diagnostic et 
thérapie. Deux autres journalistes (BEUCKER et ÜBERALL) se penchent sur la fonctionnarisation de la sphère politique où ils voient l'origine de cet immobilisme qui frappe une société "bloquée ", à en croire l'historien et sociologue NOLTE qui propose en remède le retour à la responsabilité individuelle du citoyen et au goût du risque. Les citoyens pourraient ainsi se réconcilier avec un libéralisme respectueux du social, et le capitalisme « rhénan » renouer avec la compétitivité, avance, quant à lui, le rédacteur en chef du Financial Times Deutschland (KEESE). Les économistes se concentrent, eux, sur les réformes structurelles. Sous la houlette de N. WALTER, les chercheurs de la Deutsche Bank expliquent à un large public les mécanismes qui ont grippé la croissance et la démarche à suivre pour dégager une nouvelle dynamique. Quant à l'institut de conjoncture ZEW, il a réuni les contributions d'une quinzaine de scientifiques en un «mémorandum de politique économique (FITZENBERGER et al.) à destination des décideurs. (IB) 